lipid concentration in the serum. The rareness of this entity is corroborated by one of us (I.R.) who has been examining synovial fluid for crystals for over 15 years and has never seen this form of crystal before.

\section{Joe Dylewski}

Chief of Laboratories

Indrojit Roy

Division of Pathology

St. Mary's Hospital Center

Montréal, Que.

\section{Reference}

1. Dylewski J, Awan Z, Roy, I. Acute monoarticular arthritis caused by Maltese cross-like crystals. CMA7 2005;172(6):741-2

DOI:10.1503/cmaj.1050181

\section{Coxibs and cardiovascular risk}

$\mathrm{J}_{\mathrm{h}}^{\mathrm{ill}}$ 11 Cotter and Eric Wooltorton ${ }^{1}$ highlight the importance of differences in cyclooxygenase 2 (COX-2) selectivity as a potential explanation for the prothrombotic effects of coxibs. However, they neglect important evidence that celecoxib might not share the same cardiovascular (CV) risk as rofecoxib.

An increased thrombotic risk with celecoxib has been demonstrated only in the APC (Adenoma Prevention with Celecoxib) study. ${ }^{2}$ On the other hand, data from the CLASS trial ${ }^{3}$ and a metaanalysis of multiple controlled trials ${ }^{4}$ have not uncovered any prothrombotic effect of celecoxib compared with either conventional NSAIDs or placebo. This is consistent with many observational studies that found increased $\mathrm{CV}$ risk with both high and low doses of rofecoxib but not with celecoxib. ${ }^{5-7}$

It is noteworthy that the APC trial demonstrated a trend toward increased
$\mathrm{CV}$ risk of celecoxib among ASA users. Celecoxib might have caused this effect by interference with ASA-induced inactivation of platelet COX-1, which can occur at significantly lower concentrations of celecoxib than are necessary for inhibition of platelet COX-1 activity. ${ }^{8}$ This notion does not contradict our previously stated view that ASA might mitigate $\mathrm{CV}$ risk associated with coxibs. ' However, a recent case-control study showed that the risk-modifying effects of ASA were seen only at a low dose but not at a high dose of rofecoxib. ${ }^{7}$ We have, therefore, suggested that higher doses of coxibs could also interfere with the anti-inflammatory effects of ASA mediated by $\mathrm{COX}-2 .{ }^{10}$

\section{Michal R. Pijak}

Consultant in Rheumatology, Allergy and Clinical Immunology

Division of Clinical Immunology

Department of Internal Medicine

University Hospital Bratislava

Bratislava, Slovakia

Igor Huzicka

Internist

Bratislava, Slovakia

Frantisek Gazdik

Associate Professor

Institute of Preventive and Clinical

Medicine

Slovak Medical University

Bratislava, Slovakia

\section{References}

1. Cotter J, Wooltorton E. New restrictions on celecoxib (Celebrex) use and the withdrawal of valdecoxib (Bextra). CMAJ 2005;172(10):1299.

2. Solomon SD, McMurray JJ, Pfeffer MA, Wittes $\mathrm{J}$, Fowler R, Finn P, et al. Cardiovascular risk associated with celecoxib in a clinical trial for colorectal adenoma prevention. $N$ Engl $7 \mathrm{Med}$ 2005;352:1071-80.

3. Silverstein FE, Faich G, Goldstein JL, Simon LS, Pincus T, Whelton A, et al. Gastrointestinal toxicity with celecoxib vs nonsteroidal anti-inflammatory drugs for osteoarthritis and rheumatoid arthritis: the CLASS study: a randomized controlled trial. Celecoxib Long-term Arthritis
Safety Study. FAMA 2000;284(10):1247-55.

4. White WB, Faich G, Borer JS, Makuch RW Cardiovascular thrombotic events in arthritis trials of the cyclooxygenase- 2 inhibitor celecoxib. Am 7 Cardiol 2003;92:411-8.

5. Solomon DH, Schneeweiss S, Glynn RJ, Kiyot Y, Levin R, Mogun H, et al. Relationship between selective cyclooxygenase-2 inhibitors and acute myocardial infarction in older adults. Circulation 2004;109:2068-73.

6. Kimmel SE, Berlin JA, Reilly M, Jaskowiak J, Kishel L, Chittams J, et al. Patients exposed to rofecoxib and celecoxib have different odds of nonfatal myocardial infarction. Ann Intern Med 2005;142:157-64.

7. Levesque LE, Brophy JM, Zhang B. The risk for myocardial infarction with cyclooxygenase- 2 inhibitors: a population study of elderly adults. Ann Intern Med 2005;142:481-9.

8. Ouellet M, Riendeau D, Percival MD. A high level of cyclooxygenase-2 inhibitor selectivity is associated with a reduced interference of platelet cyclooxygenase-1 inactivation by aspirin. Proc Natl Acad Sci U S A 2001;98:14583-8.

9. Pijak MR, Gazdik F. COX-2 inhibitors and type 4 error. CMAf 2003;169(3):190.

10. Pijak MR, Huzicka I, Gazdik F. The risk of myocardial infarction with cyclooxygenase- 2 inhibitors [electronic letter]. Available: www.annals .org/cgi/eletters/142/7/481\#1555 (posted 2005 Apr 30; accessed 2005 May 2).

Competing interests: None declared for Drs. Huzicka and Gazdik. Dr. Pijak has received speaker fees and travel assistance from Fournier.

DOI:10.1503/cmaj.1050128

Jil ill Cotter and Eric Wooltorton ${ }^{1}$ indicated that COX-2 inhibitors appear to increase the risk of cardiovascular adverse events in a dose-related fashion. The CLASS and VIGOR clinical trials of COX-2 inhibitor(s) suggested that both celecoxib and rofecoxib can increase the risk of cardiovascular events. ${ }^{2}$ The VIGOR trial compared rofecoxib with the NSAID naproxen in patients with rheumatoid arthritis ${ }^{3}$ and indicated a 5fold increase in the relative risk of developing serious cardiovascular events between the rofecoxib group and the naproxen group.

Clinical data have shown that expression of COX-2 is upregulated by inducible nitric oxide synthase (iNOS) that might play a protective role in the 
cardiovascular system. ${ }^{4}$ However, the COX-2 enzyme might be exerting detrimental effects elsewhere, because analysis of protein extracts from normal arteries has revealed constitutive COX1 only, but atheromatous lesions contained both COX-1 and COX-2 protein. ${ }^{5}$ Some studies suggest that prostanoids and nitric oxide may have proatherosclerotic effects ${ }^{6}$ resulting from the formation of peroxynitrite species in the affected vessels, possibly involving "cross talk" between the COX-2, iNOS and other enzyme systems, which may generate oxidants including dihydrogen trioxide and even ozone from singlet oxygen and water in atheromatous plaques.

Well-planned basic research is essential to show whether COX-2 activity is beneficial or harmful for the cardiovascular system in different sites or in cardiovascular disease and to exploit the benefits of COX-2 inhibitor therapy.

\section{Syed A.H. Zaidi}

Department of Pharmacology

University of Oxford

Oxford, UK

\section{References}

1. Cotter J, Wooltorton E. New restrictions on celecoxib (Celebrex) use and the withdrawal of valdecoxib (Bextra). CMA7 2005;172(10):1299.

2. Mukherjee D, Nissen SE, Topol EJ. Risk of cardiovascular events associated with selective COX-2 inhibitors [review]. 7AMA 2001;286(8): 954-9. [Summary for patients in: Can Fam Physician 2002;48:1449-51.]

3. Bombardier C, Laine L, Reicin A, Shapiro D, Burgos-Vargas R, Davis B, et al; VIGOR Study Group. Comparison of upper gastrointestinal toxicity of rofecoxib and naproxen in patients with rheumatoid arthritis. VIGOR Study Group. $N$ Engl $7 \mathrm{Med}$ 2000343(21):1520-8, 2 p following 1528.

4. Bolli R, Shinmura K, Tang XL, Kodani E, Xuan YT, Guo Y, et al. Discovery of a new function of cyclooxygenase (COX)-2: COX-2 is a cardioprotective protein that alleviates ischemia/reperfusion injury and mediates the late phase of preconditioning. Cardiovasc Res 2002;55(3):506-19.

5. Schonbeck U, Sukhova GK, Graber P, Coulter S, Libby P. Augmented expression of cyclooxygenase-2 in human atherosclerotic lesions. $A m \mathcal{F}$ Pathol 1999;155(4):1281-91.

6. Baker CS, Hall RJ, Evans TJ, Pomerance A, Maclouf J, Creminon C, et al. Cyclooxygenase-2 is widely expressed in atherosclerotic lesions affecting native and transplanted human coronary arteries and colocalizes with inducible nitric oxide synthase and nitrotyrosine particularly in macrophages. $A r$ - terioscler Thromb Vasc Biol 1999;19(3):646-55.

7. Wentworth P Jr, Nieva J, Takeuchi C, Galve R, Wentworth AD, Dilley RB, et al. Evidence for ozone formation in human atherosclerotic arteries. Science 2003;302(5647):1053-6.

Competing interests: None declared.

DOI:10.1503/cmaj.1050143

$\mathrm{J}$ ill Cotter and Eric Wooltorton suggest an approach to prescribing COX-2 inhibitors that includes estimating cardiac risk, using the lowest doses for short periods, and discussing the risks and benefits of long-term use. They provide evidence for the cardiovascular risks of celecoxib. ${ }^{1}$ Regarding the benefits, it is helpful to review the results of the CLASS trial, ${ }^{2}$ which was designed to evaluate the efficacy of celecoxib in reducing clinically significant upper gastrointestinal (GI) adverse events.

CLASS reported the pooled results of 2 trials comparing celecoxib, $400 \mathrm{mg}$ twice a day, with diclofenac, $75 \mathrm{mg}$ twice a day, and ibuprofen, $800 \mathrm{mg}$ three times a day. The study protocol prespecified that the results would be pooled, but an FDA report ${ }^{3}$ gave the results separately for diclofenac and ibuprofen, for the full length of the 2 studies, 12 months and 15 months, whereas the published CLASS study reported 6month data.

The FDA report concludes that the CLASS trial was a robust testing of the safety of celecoxib at doses 2 and 4 times those currently labelled for rheumatoid arthritis and osteoarthritis, respectively; celecoxib does not appear to be more effective for treating the signs and symptoms of osteoarthritis or rheumatoid arthritis than the NSAID comparators; and celecoxib did not show statistically significant superiority to diclofenac at any point in the trial regardless of ASA use or end point (including the primary end point of clinically significant upper GI events, namely, upper GI bleeding, perfora- tion, or gastric outlet obstruction alone or with gastroduodenal ulcers).

With little indication of benefit in symptom control or reduction of adverse events, it is questionable whether there is a need to prescribe celecoxib at all.

Michael J. Allen

Dalhousie University Office of CME

Halifax, NS

Pamela McLean-Veysey

Team Leader, Drug Evaluation Unit QEII Health Sciences Centre

Halifax, NS

Isobel Fleming

Senior Detailer, Dalhousie Academic

Detailing Service

Dalhousie University Office of CME

Halifax, NS

\section{References}

1. Cotter J, Wooltorton E. New restrictions on celecoxib (Celebrex) use and the withdrawal of valdecoxib (Bextra). CMA7 2005;172(10):1299.

2. Silverstein FE, Faich G, Goldstein JL, Simon LS, Pincus T, Whelton A, et al. Gastrointestinal toxicity with celecoxib vs nonsteroidal anti-inflammatory drugs for osteoarthritis and rheumatoid arthritis. The CLASS study: a randomized controlled trial. FAMA 2000;284:1247-55.

3. Food and Drug Administration. Celebrex capsules (Celecoxib). Medical Officer Review. 14-6-2000. Available: www.fda.gov/ohrms/dockets/ac/01 /briefing/3677b1_03_med.pdf (accessed 2005 June 1).

Competing interests: None declared.

DOI:10.1503/cmaj.1050119

\section{The wrong stuff}

Tf Dr. Ursus gets upset and anxious, indeed paranoid, about misdiagnosing the very early manifestations of an extraordinarily rare disorder such as Guillain-Barré syndrome, ${ }^{1}$ he won't last long in this job.

\section{Ian McM. Connor}

Pediatrician

Sarnia, Ont.

\section{Reference}

1. Query. CMAf 2005;172(12):1648.

DOI:10.1503/cmaj.1050147 